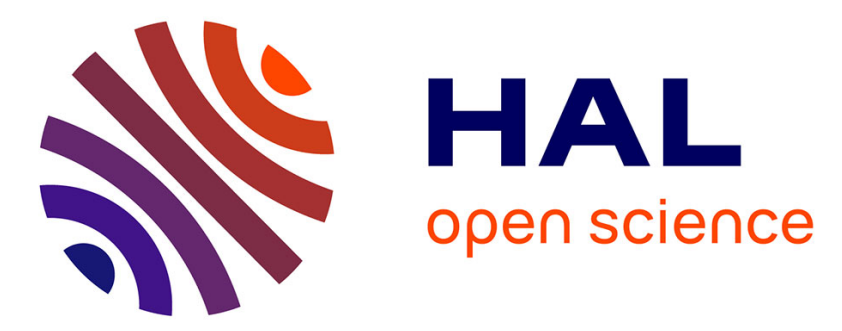

\title{
Projection of the daily travel of an ageing population: The Paris and Montreal case, 1975-2020
}

Virginie Dejoux, Yves Bussiere, Jean-Loup Madre, Jimmy Armoogum

\section{To cite this version:}

Virginie Dejoux, Yves Bussiere, Jean-Loup Madre, Jimmy Armoogum. Projection of the daily travel of an ageing population: The Paris and Montreal case, 1975-2020. Transport Reviews, 2010, vol30 (n.4), pp 495-515. 10.1080/01441640903166724 . hal-00559492

\section{HAL Id: hal-00559492 https://hal.science/hal-00559492}

Submitted on 25 Jan 2011

HAL is a multi-disciplinary open access archive for the deposit and dissemination of scientific research documents, whether they are published or not. The documents may come from teaching and research institutions in France or abroad, or from public or private research centers.
L'archive ouverte pluridisciplinaire HAL, est destinée au dépôt et à la diffusion de documents scientifiques de niveau recherche, publiés ou non, émanant des établissements d'enseignement et de recherche français ou étrangers, des laboratoires publics ou privés. 
Ed. Taylor and Francis , Transport Reviews, vol30, n4 , pp 495-515 DOI: 10.1080/01441640903166724

\title{
Projection of the daily travel of an ageing population: \\ The Paris and Montreal case, 1975-2020.
}

\author{
Virginie Dejoux ${ }^{\diamond}$, Yves D. Bussière ${ }^{\diamond}$, Jean-Loup Madre and Jimmy Armoogum \\ INRETS-DEST (Paris, France) \\ ${ }^{\infty}$ Facultad de Economía, BUAP (Puebla, Mexico)
}

Virginie Dejoux

INRETS - DEST

Site de Marne-la-Vallée. «Le Descartes 2 »

2 rue de la Butte Verte

93166 Noisy le grand cedex

Phone : 33145925588

Email : virginie.dejoux@inrets.fr

Yves Bussière

Fac of Economics, BUAP

Ciudad Universitaria, Puebla, Mexico 72570

Phone : 522225708075

Email : ydbussiere@yahoo.ca

Jean-Loup Madre

INRETS - DEST

Site de Marne-la-Vallée. "Le Descartes 2 »

2 rue de la Butte Verte

93166 Noisy le grand cedex

Phone : 33145925553

Email : jean-loup.madre@inrets.fr

Jimmy Armoogum

INRETS - DEST

Site de Marne-la-Vallée. «Le Descartes 2 »

2 rue de la Butte Verte

93166 Noisy le grand cedex

Phone : 33145925579

Email : jimmy.armoogum@inrets.fr 


\section{Abstract:}

Ageing of the population, urban sprawl and car dependency will change travel patterns. The main objective of this paper is to give elements for a better understanding of the impact of changing demographics on the long term evolution of daily mobility using demographic-based models to forecast, for the elderly population, car-ownership, trip frequency, distance traveled, average trip distance. A second objective is to measure the impact of the long term tendencies observed on the appearance of new needs of travel demand such as a rapid increase of demand-responsive transport. The paper compares two agglomerations, both in a strong ageing process, but in quite different sociocultural contexts: a large European metropolis: Paris, and a medium sized north-american city: Montreal. Many common conclusions derived from the two different cases studies reinforce the possibility of generalizing the conclusions to other situations. 


\section{INTRODUCTION}

This paper has two main objectives: The first objective is to give elements for a better understanding of the impact of changing demographics, focusing on the elderly population, on the long term evolution of daily mobility using demographic-based models to forecast mobility patterns such as car-ownership, trip frequency, distance traveled, average trip distance. A second objective is to measure the impact of the long term tendencies observed on the appearance of new needs of travel demand such as a rapid increase of demand-responsive transport.

The analysis is based on two case studies both in a strong ageing process, but in quite different socio-cultural contexts: a large European metropolis: Paris, and a medium-sized northamerican city: Montreal. The interest of comparing two quite different case studies is that common conclusions may reinforce the possibility of generalizing the results to other situations and different conclusions may help to understand the impact of the ageing process on urban mobility:

-The first case study is in North America, the Metropolitan Region of Montreal (MRM), with a population of 3,3 million, characterised by low population density with urban sprawl where car use started to expand earlier than in Europe (in the 1930s), with low fertility rates and high immigration and where ageing is accelerating and will soon surpass what is observed in European cities,

-The second case study is in Europe, the Greater Paris Region (GPR) or lle-de-France (IDF), with a population of 11 million, characterised by much higher urban densities at least in the central city, where the average age of individuals is currently higher than in Montreal, and where the demographic dynamism is based more on fertility than immigration.

These two case studies were chosen for three main reasons: their representativeness of a relatively low density North American city and a high density European city, both with a good supply of public transport, the presence of strong ageing in a context of urban sprawl and, finally, the availability of comparable data from O-D surveys over a long period.

In fact, in both regions of study ageing has already started and should continue as we can see in the graph 1 showing the evolution between 2005 and 2020. This ageing process is more pronounced in MRM than in IDF in 2005 and at the horizon 2025 the trend continues with a time- lag of roughly 10 years. 
Graph 1: Ageing of the population in GPR and MRM in 2005 and 2020 (\% of total population by age group)
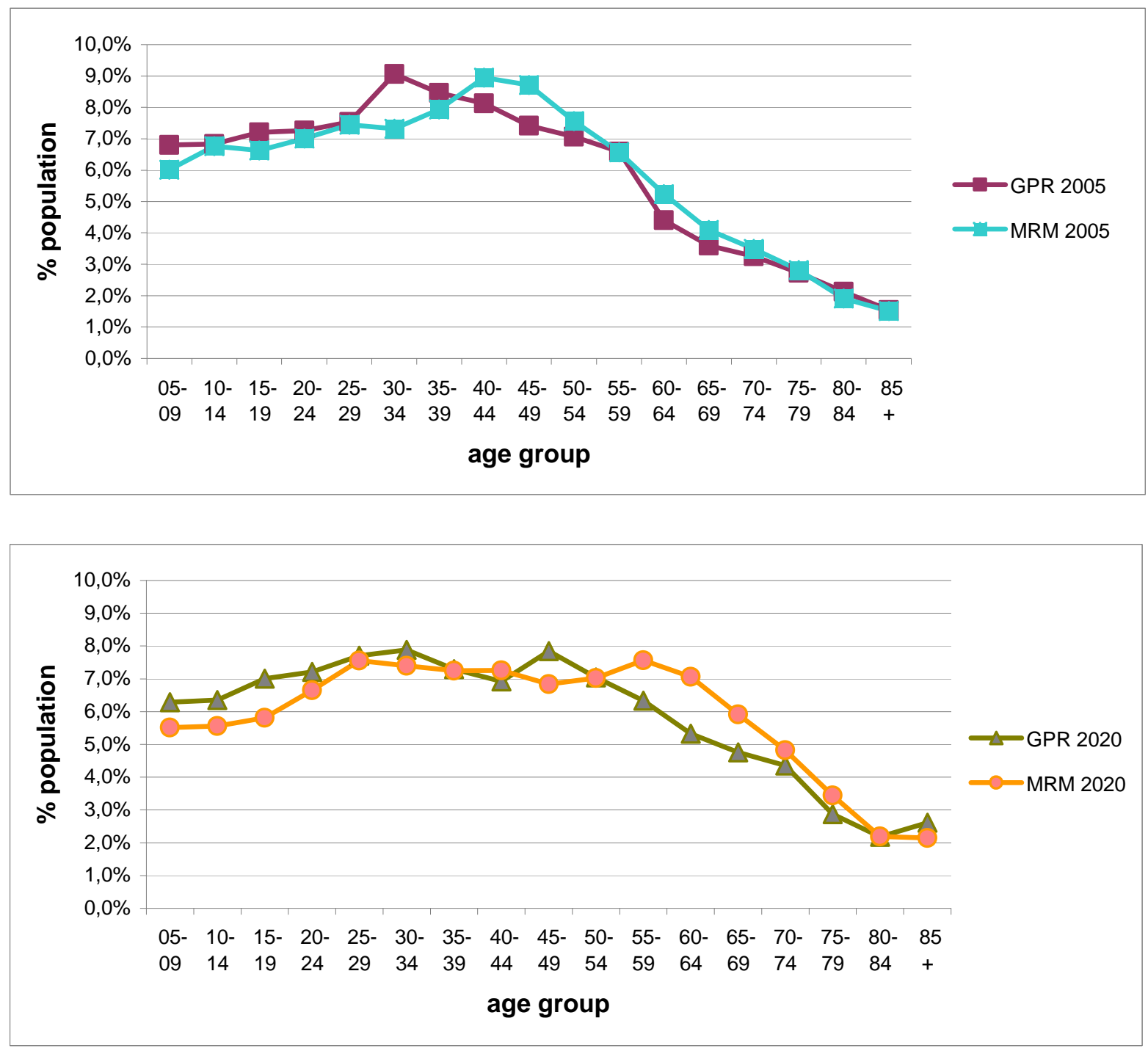

The quantitative study of the project "Life quality of senior citizens in relation to mobility conditions" that was conducted in 9 Europeans countries in 2004 showed that senior citizens want to stay autonomous and independent as long as possible (Grönvall and al, 2005, Grönvall and al, 2006). However, several studies outline the presence of many barriers to mobility for displacements outside the home (Stahl et al., 2008). Also, with ageing, people experience physical, financial, emotional, and mental barriers to driving and the majority eventually have to stop driving (Bush, 2003) The same observations are made in the United States: based on a series of regional forums, focus groups, conferences, and stakeholder roundtables, the U.S. Department of Transportation lists the necessary progress for a transportation system that allows older persons to remain independent and to age at home (U.S. Department of Transportation, 2003). 
Ageing of the population, urban sprawl and car dependency will change travel patterns. To illustrate this phenomenon, we applied a demographic-based projection model of travel behaviour for the period 1975-2020 in Paris and 1976-2021 in Montreal, measuring various elements of daily mobility such as car ownership, trip frequency, distance travelled, average trip distance. The model, based on demographic trends in a longitudinal analysis reveals the complex role of the age factor which, in a dated temporal context, consists of a combination of three interlinked dimensions:

- the stage in the life cycle, which expresses the influence of age on travel behaviour. By evaluating the effects of the stage in the life cycle, it is possible to obtain a characteristic curve for those changes which can be related to age (we shall refer to this as the standard life profile);

- the generation (or cohort), which takes into account travel behaviour on the basis of membership of a group of individuals born during the same period, who therefore share a common "life experience". Introducing this generation gap effect (which can be measured by means of differentials) allows us to place this profile in a long term perspective;

- the Age-Cohort model supposes age and generation behaviours stable through time;

- a more complete Age-Cohort-Period model, which is not considered here, would take into account the period effect, which expresses the influence of the overall economic context on behavioural changes. In such a model the period effect expresses the importance of socio-economic factors which affect all individuals and households simultaneously (e.g. changes in legislations, cost of fuel).

Furthermore, ageing of the population in a context of continuing urban sprawl and car dependency suggest that the need for demand-responsive transport may grow rapidly in future years (Bush, 2003). Ageing will change travel patterns and may induce new needs in terms of demandresponsive transport (ECMT, 2000). For example, with the disappearance of public transport, taxi use has greatly increased in certain rural areas, where the elderly population is highly concentrated (Bussière and Thouez, 2004).

Fortunately, in large metropolises, the disappearance of public transport is not on the agenda but strong ageing will induce new needs and the long term trends that affect the daily travel of the elderly population will likely affect demand-responsive transport. 


\section{Demographic changes in the Greater Paris Region and the Metropolitan Region of Montreal}

The minimum age to be surveyed is slightly lower in Montreal than in Paris: OD surveys coverage are persons 5 and over in the MRM and 6 and over in the GPR. The surveyed population in the Greater Paris Region (GPR) is projected to increase from 8.6 million in 1975 to 11.1 million in 2020 and in the Metropolitan Region of Montreal (MRM) from 2.7 million in 1976 to 3.3 million in 2021 (Table 1). Urban sprawl is also clearly apparent, above all between 1975 and 1990, but continuing even until 2021 when the outer suburbs should count for $48.4 \%$ of the population in the GPR as well as in MRM.

The average age has increased from 37.7 to 41.2 in the GPR and 34.0 to 43.2 in the MRM. Ageing will be greater in the MRM than in the GPR, a direct consequence of the very low fertility rates which followed the baby-boom in Montreal, while it has stayed around 2 in France, which is now the highest rate in Europe (Table 2). While at the start of the period, average age was considerably higher in the central cities than in the inner or the outer suburbs, it should become more homogeneously high in almost all parts of the territory at the end of the period under consideration. The levels in the MRM will become comparable with the GPR with an average age in the suburbs higher than in the GPR. This situation is the result of sustained low fertility rates and of a large number of young immigrants settling in the central city of Montreal (Chapleau, 1990).

Table 1: The population in the Greater Paris Region (GPR) and in the Metropolitan Region of Montreal (MRM)

by gender and zone of residence

\begin{tabular}{|l|c|c|r|r|r|r|r|r|}
\hline Population (thousands) & \multicolumn{4}{|c|}{ GPR } & \multicolumn{4}{c|}{ MRM } \\
\hline By zone of residence & $\mathbf{1 9 7 5}$ & $\mathbf{1 9 9 0}$ & $\mathbf{2 0 0 5}$ & $\mathbf{2 0 2 0}$ & $\mathbf{1 9 7 6}$ & \multicolumn{1}{c|}{$\mathbf{1 9 9 1}$} & \multicolumn{1}{c|}{$\mathbf{2 0 0 6}$} & $\mathbf{2 0 2 1}$ \\
\hline Central city & 2088 & 1944 & 1988 & 1910 & 1156 & 974 & 968 & 981 \\
\hline Inner suburbs & 3433 & 3549 & 3778 & 3795 & 649 & 701 & 722 & 729 \\
\hline Outer suburbs & 3079 & 3891 & 4705 & 5346 & 851 & 1273 & 1511 & 1603 \\
\hline All & 8599 & 9384 & 10471 & 11051 & 2656 & 2948 & 3201 & 3313 \\
\hline
\end{tabular}

Source: Population projections based on censuses.

Table 2: Average age of the different population groups in the Greater Paris Region (GPR) and in the

Metropolitan Region of Montreal (MRM) by zone of residence

\begin{tabular}{|l|c|c|c|c|c|c|c|c|}
\hline Average age & \multicolumn{4}{|c|}{ GPR } & \multicolumn{4}{c|}{ MRM } \\
\hline By zone of residence & $\mathbf{1 9 7 5}$ & $\mathbf{1 9 9 0}$ & $\mathbf{2 0 0 5}$ & $\mathbf{2 0 2 0}$ & $\mathbf{1 9 7 6}$ & $\mathbf{1 9 9 1}$ & $\mathbf{2 0 0 6}$ & $\mathbf{2 0 2 1}$ \\
\hline Central city & 43.0 & 40.4 & 41.4 & 43.3 & 37.1 & 41.1 & 41.5 & 43.0 \\
\hline Inner suburbs & 37.6 & 37.5 & 39.2 & 40.9 & 33.1 & 38.7 & 41.6 & 44.2 \\
\hline Outer suburbs & 34.3 & 36.0 & 38.4 & 40.6 & 30.6 & 35.5 & 39.4 & 42.9 \\
\hline All & 37.7 & 37.5 & 39.2 & 41.2 & 34.0 & 38.1 & 40.5 & 43.2 \\
\hline
\end{tabular}

Source: Population projections based on censuses. 
These tendencies should lead to a higher percentage of elderly in the MRM than in the GPR in 2021 (Tables 3 and 4). The population aged 65 and over will thus account for $19.0 \%$ of the surveyed population in 2021 in the MRM compared with $16.8 \%$ in the GPR in 2020. Ageing should be important in all zones with a very high augmentation in the population aged 75 and over which will increase from $4.7 \%$ to $7.7 \%$ of the surveyed population in the GPR and from $2.2 \%$ to $8.0 \%$ in the MRM. In both cases, the ageing should be more important in the inner and outer suburbs than in the central city. Thus, In the outer suburbs, the population aged 65 and over will increase from $9.1 \%$ of the surveyed population in 1975 to $16.7 \%$ in 2020 in the GPR and respectively in the MRM from $4.5 \%$ in 1976 to $18.2 \%$ in 2021.

Table 3: Distribution of the population in the Greater Paris Region by three age groups and zone of residence

\begin{tabular}{|l|r|r|r|r|r|r|r|r|}
\hline Age group & \multicolumn{4}{|c|}{$\mathbf{6 5 - 7 4}$} & \multicolumn{4}{c|}{$\mathbf{7 5}$ and over } \\
\hline Year & $\mathbf{1 9 7 5}$ & $\mathbf{1 9 9 0}$ & $\mathbf{2 0 0 5}$ & $\mathbf{2 0 2 0}$ & $\mathbf{1 9 7 5}$ & $\mathbf{1 9 9 0}$ & $\mathbf{2 0 0 5}$ & $\mathbf{2 0 2 0}$ \\
\hline $\begin{array}{l}\text { By zone of } \\
\text { residence }\end{array}$ & & & & & & & & \\
\hline Paris & $12.5 \%$ & $7.4 \%$ & $7.2 \%$ & $9.6 \%$ & $7.2 \%$ & $7.4 \%$ & $8.0 \%$ & $8.3 \%$ \\
\hline Inner suburbs & $8.4 \%$ & $4.8 \%$ & $6.9 \%$ & $8.7 \%$ & $4.3 \%$ & $4.8 \%$ & $6.6 \%$ & $7.6 \%$ \\
\hline Outer suburbs & $5.8 \%$ & $4.0 \%$ & $6.6 \%$ & $9.2 \%$ & $3.3 \%$ & $4.0 \%$ & $5.5 \%$ & $7.5 \%$ \\
\hline All & $8.5 \%$ & $6.1 \%$ & $6.8 \%$ & $9.1 \%$ & $4.7 \%$ & $5.0 \%$ & $6.4 \%$ & $7.7 \%$ \\
\hline
\end{tabular}

Source: Population projections based on censuses.

Table 4: Distribution of the population of the Metropolitan Region of Montreal according to three age groups and zone of residence

\begin{tabular}{|l|c|c|c|c|c|c|c|c|}
\hline Age group & \multicolumn{4}{|c|}{$\mathbf{6 5 - 7 4}$} & \multicolumn{3}{c|}{$\mathbf{7 5}$ and over } \\
\hline Year & $\mathbf{1 9 7 6}$ & $\mathbf{1 9 9 1}$ & $\mathbf{2 0 0 6}$ & $\mathbf{2 0 2 1}$ & $\mathbf{1 9 7 6}$ & $\mathbf{1 9 9 1}$ & $\mathbf{2 0 0 6}$ & $\mathbf{2 0 2 1}$ \\
\hline $\begin{array}{l}\text { By zone of } \\
\text { residence }\end{array}$ & & & & & & & & \\
\hline \multicolumn{1}{|c|}{ Central city } & $8.0 \%$ & $9.6 \%$ & $7.7 \%$ & $9.8 \%$ & $3.2 \%$ & $7.2 \%$ & $8.2 \%$ & $8.7 \%$ \\
\hline Inner suburbs & $4.5 \%$ & $7.9 \%$ & $8.7 \%$ & $11.7 \%$ & $1.8 \%$ & $4.8 \%$ & $7.5 \%$ & $9.3 \%$ \\
\hline Outer suburbs & $3.3 \%$ & $5.3 \%$ & $7.0 \%$ & $11.3 \%$ & $1.2 \%$ & $2.8 \%$ & $4.6 \%$ & $6.9 \%$ \\
\hline All & $5.6 \%$ & $7.3 \%$ & $7.6 \%$ & $11.0 \%$ & $2.2 \%$ & $4.7 \%$ & $6.4 \%$ & $8.0 \%$ \\
\hline
\end{tabular}

Source: Population projections based on censuses.

\section{Travel demand modelling}

The main idea of the study was to make the best use of the factors of age (with its components of life cycle, generation and period mentioned above), gender, and spatial distribution to describe the dynamics of car ownership (Madre, 1990; Gallez, 1994; Bussière, Armoogum and Madre 1996), travel behaviour and modal split (Madre, Bussière and Armoogum 1995; Krakutovski, 2004). 
Trip making is highly constrained by the available means of transport, particularly the availability of a car (Bonnafous, 1992). Car ownership rate thus appears to be a "key" variable with regard to travel behaviour. We shall therefore examine the car ownership of individuals in relation to travel behaviour on the basis of trip frequency measurements and distances travelled, first, globally and then by modal split.

\subsection{Presentation of the age-cohort model}

The model used is essentially based on an age-cohort approach taking into account the impact of the life-cycle and generation effects through time on travel behavior, which permits to outline the impact of age and generation combined with various structural variables: gender, spatial distribution, motorization of the households ...

We used a variance analysis model which is written as follows:

$$
\pi_{a, k}=\sum_{a \in A} \alpha_{a} I_{a}+\sum_{k \in K} \gamma_{k} I_{k}+\varepsilon_{a, k}
$$

Where:

- $\pi_{\mathrm{a}, \mathrm{k}}$ : measures a characteristic or behavior (daily kilometers, number of trips per day,...); "a" is the age band of the individual reflecting the life-cycle and " $k$ " his generation, defined by his date of birth;

- $\alpha_{a}$ : measures the behavior of a generation of reference at the age band "a". This allows us to calculate a « Standard Profile » of the life cycle;

- $\mathrm{I}_{\mathrm{a}}$ : are the dummy variable of the age band "a".

- $\gamma_{\mathrm{k}}$ : measures the gap between the cohort " $\mathrm{k}$ " and the generation of reference $\gamma_{\mathrm{k}^{0}}$;

- $\mathrm{I}_{\mathrm{k}}$ : are the dummy variable of the cohort " $\mathrm{k}$ ".

- $\varepsilon_{\mathrm{a}, \mathrm{k}}$ : is the residual of the model (which includes all other factors).

The unit of measurement used is the standard five years cohort used in demographic analysis. It was used both for the definition of the generations and for the description of the standard life profiles, with the exception of age groups with small samples which required to be aggregated (individuals aged 85 years and older were classified in the age group "85 and over", and the individuals born before 1907 were grouped with the generation group "1907-1911"). 
In order to be able to distinguish between life-cycle and generation effects, the calibration of an Age-Cohort model (based on the analysis of variance) requires data on the mobility behavior of individuals for at least two observation periods. With only two observations, there is no residue. It is preferable to have three or more observations to obtain a residual term taking into account factors not included in the model (i.e. income or price effects). In the two case studies chosen more than three surveys were used; Paris (Paris metropolitan region, or lle-de-France, with 4 Global surveys, 1976-77, 1983-84, 1991-92, 1997-98) and Montreal (Montreal metropolitan region: with 6 origin-destination surveys: $1974,1978,1982,1987,1993,1998)$. The sample size for the Global surveys in Paris are around 10000 respondent households (except for 1998 with 3500 ) and in the 50000 to 60000 range for Montreal. The model for each case study was calibrated with these O-D surveys, which furnish detailed data on travel behavior on a typical week-day, and detailed demographic data by quinquennal age groups (observed and projected).

The following variables have been considered in the model's specification:

- age (with its life cycle and generational components) and gender;

- zone of residence: we have identified 3 concentric zones with diminishing density from the center to the outer suburbs. The densier zone is the central city (City of Paris - 200 pers./ha.; the central zone of the Island of Montreal - 63 pers./ha.), the inner suburbs show less density (the inner suburbs in Paris with 63 pers./ha., and the rest of the Island of Montreal with 22 pers./ha.) and the outer suburbs with very low densities (the rest of the region) with approximately 5 pers./ha.;

- level of motorization of the households ( 0 car, 1 car, 2 cars or more). This criterion, a proxy for the individual access to automobile, proves quite discriminatory relative to the zone of residence and the distance travelled which increases with motorization.

In both case studies age and gender should have similar impacts on travel demand patterns as well as the levels of motorization which rise as we get farther from the center. The main difference in the two case studies is the population density which is much higher in Paris in the central city and in the inner suburbs and the level of supply of public transport, which is much higher in Paris than in Montreal.

We have run 18 models of variance analysis by crossing the following variables: three zones of residence, three levels of motorization and two genders. Therefore, there is no direct evaluation of the "goodness of fit" of the model on the overall population. It is a pseudo-panel, not a panel survey 
approach; thus variability inside these categories is still important, but a great part of it is explained by the 4 dimensions (age, gender, residence location, motorisation) taken into account.

Mobility is measured by two variables:

- global mobility or frequency of trips (average number of trips per person for a typical week day);

- distance travelled (number of kilometres travelled per person for a typical week day).

\subsection{The model for Projection of Mobility}

The projection of mobility (daily kilometres, number of trips per day...) for an individual of zone of residence $(\mathrm{z})$, level of motorization $(\mathrm{v})$ and gender $(\mathrm{s})$ at the date $(\mathrm{t})$ is given by:

$$
\pi_{a, k}^{z, v, s}=\alpha_{a}^{z, v, s}+\gamma_{k}^{z, v, s}
$$

Where:

- $\mathrm{t}=\mathrm{a}+\mathrm{k}$ ( $\mathrm{a}$ is the age of the individual reflecting the life-cycle and $\mathrm{k}$ his generation, defined by his date of birth);

- $\alpha_{a}$ : measures the behavior of a generation of reference at the age a. This allows us to calculate a « Standard Profile » of the life cycle;

- $\gamma_{\mathrm{k}}$ : measures the gap between the cohort $\mathrm{k}$ and the generation of reference $\gamma_{\mathrm{k}^{0}}$;

Since the gaps in cohorts for recent generations tend to disappear we took the last observed cohorts gap for future generation (Madre \& al., 1995).

The mobility for the population at the date $t$ is estimated as follow:

$$
M_{t}=\frac{\sum_{z=1}^{3} \sum_{v=0}^{2} \sum_{s=1}^{2}\left(P_{a, t}^{z, v, s} * \pi_{a, k=t-a}^{z, v, s}\right)}{\sum_{z=1}^{3} \sum_{v=0}^{2} \sum_{s=1}^{2} P_{a, t}^{z, v, s}}
$$

Where:

- $\quad P_{a, t}^{z, v, s}$ is the population projection of zone of residence $\mathrm{z}$, level of motorization $\mathrm{v}$ and gender $\mathrm{s}$ at the date t. 


\subsection{Model fitting}

As the model only provides quinquennal results, we had to estimate the results for the survey years by linear interpolation. To make a more comprehensive comparison between the observations and the results of the model, we calculated regressions between the observed values and the model's estimates at the most detailed level, i.e. by crossing the following variables:

- zone of residence (3 zones);

- $\quad$ car ownership (3) - (0, one or several cars in the household);

- $\quad$ gender (2);

- five-year age groups (17);

- $\quad$ survey dates (4 or 5$)$.

We had approximately 1200 points for the Greater Paris Region (4 surveys) and 1800 points for the Metropolitan Region of Montreal (based on the six O-D surveys). To validate the model we need that:

- $\quad$ the $R^{2}$ value be close to 1 ;

- the gradient be close to 1 ;

- $\quad$ the constant be not significantly different from 0 .

The "Age-Cohort" model seems well suited for travel demand forecasting as all the above conditions were met (see Table 5), with the exception of the constant relative to the number of trips in Montreal which appears to be significantly different from 0 at the $5 \%$ level.

Table 5: Regression between the observed values and the age-cohort model estimations, GPR and MRM

\begin{tabular}{|l|c|c|c|c|c|}
\hline \multirow{2}{*}{ Model: } & \multirow{2}{*}{$\mathrm{R}^{2}$} & \multicolumn{2}{|c|}{ Gradient } & \multicolumn{2}{c|}{ Constant } \\
\cline { 3 - 6 } & & $\begin{array}{c}\text { Estimate of } \\
\text { parameter }\end{array}$ & $\begin{array}{c}\text { Value of } \\
\mathrm{t}\end{array}$ & $\begin{array}{c}\text { Estimate of } \\
\text { parameter }\end{array}$ & Value of $\mathrm{l}$ \\
\hline Greater Paris Region & \multicolumn{5}{|l|}{0.04} \\
\hline Number of trips & 0.88 & 1.00 & 93.6 & 0.00 & 1.35 \\
\hline Distance travelled & 0.97 & 1.00 & 210.5 & 0.11 & 23.2 \\
\hline Metropolitan Region of Montreal \\
\hline Number of trips & 0.88 & 0.91 & 211.5 & 0.22 & 10.6 \\
\hline Distance travelled & 0.97 & 0.99 & 433.3 & 0.31 & \\
\hline
\end{tabular}

Sources: Estimates based for GPR on Global Travel Surveys (1977, 1984, 1992 and 2002).

Estimates based on the Metropolitan Region of Montreal O-D surveys (1978, 1982, 1987, 1993 and 1998).

In an earlier publication (Madre et al., 1996), we calibrated two Age-Cohort models on the

Paris region: 1) the daily trips frequency and, 2) the daily distance travelled. For both models we used the first 3 global surveys available $(1977,1984,1992)$. The mean trips length was calculated by dividing the estimated daily distance travelled by the daily trips frequency. These calibrations indicated 
that there would be a rupture in the trend, a result which has been confirmed by recent data (1998 and 2002).

\section{Estimation of car ownership and travel in the two regions}

\subsection{Projection of car ownership}

Motorization is a determinant factor of the mobility of the elederly, and as far as we can project, the private car is likely to remain the dominant mode of transport for the elderly in most OECD countries, due especially to the expected increase in the number of licence holders among elderly (Whelan et al., 2006). The 1975-2005 period was marked by a considerable increase in car ownership in both cases under study: according to the results of the model, the number of households with one or more cars in the GPR has grown by $61.8 \%$ between 1975 and 1990 and by $15.6 \%$ between 1990 and 2005. In the MRM, car ownership was higher than in the GPR, which may explain why the respective rates of increase are lower: $12.0 \%$ and $8.3 \%$. These considerable increases in car ownership are principally due to the purchase of a second (or an additional) car.

The projected changes between 2005 and 2020 in the two regions are more contrasted (Table 6). In the Greater Paris Region, we forecast a continuation in the growth of the number of car-owning households and an even greater increase in the number of households with two or more cars. Thus, the number of households with no car could fall from 2072000 in 2005 to 2033000 in 2020 (a reduction of $2 \%$ ), while during the same period the number of households with two or more cars should increase from 3732000 to 4574000 (an increase of 23\%). In the MRM we forecast an increase in the number of households with no car $(+13 \%)$, a slight increase in the number of one-car households and a reduction in the number of multi-car households $(-1 \%)$.

Thus, in the Greater Paris Region between 2005 and 2020 the projection gives a reduction in the percentage of no car and one-car households, which could fall respectively from $19.8 \%$ to $18.4 \%$ and from $44.6 \%$ to $40.2 \%$ accompanied by a substantial increase in the percentage of multi-car households from $35.6 \%$ in 2005 to $41.4 \%$ in 2020 . In contrast, in the MRM, the percentage of households with no car could increase (from 18.5\% in 2006 to 20.2\% in 2021) and the percentage of multi-car households could decrease slightly (from $23.2 \%$ in 2006 to $22.2 \%$ in 2021).

This contrasted situation between the GPR and the MRM could be explained, at least partially, by a more pronounced ageing in the MRM (the population aged 65 and over should count for $16,8 \%$ of the population in the GPR in 2020 and $18,9 \%$ in MRM in 2021). Moreover, since the motorisation 
process has started two decades earlier in North America than in Europe, it is nearer to saturation (Berri, 2005).

Table 6: Population in the Greater Paris Region and in the Metropolitan Region of Montreal,

by car ownership

\begin{tabular}{|c|c|c|c|c|c|c|c|c|}
\hline \multirow{2}{*}{$\begin{array}{l}\text { Population (thousands) } \\
\text { Projection year }\end{array}$} & \multicolumn{4}{|c|}{ GPR } & \multicolumn{4}{|c|}{ MRM } \\
\hline & 1975 & 1990 & 2005 & 2020 & 1976 & 1991 & 2006 & 2021 \\
\hline Households with no car & 2461 & 2121 & 2072 & 2033 & 505 & 538 & 592 & 670 \\
\hline One-car households & 4510 & 4630 & 4667 & 4445 & 1578 & 1751 & 1866 & 1907 \\
\hline Multi-car households & 1628 & 2633 & 3732 & 4574 & 572 & 659 & 743 & 737 \\
\hline All & 8599 & 9384 & 10471 & 11051 & 2655 & 2948 & 3201 & 3313 \\
\hline
\end{tabular}

Sources: Estimates based for GPR on Global Travel Surveys (1977, 1984, 1992 and 2002) and population projections according to censuses.

Estimates based on the Metropolitan Region of Montreal O-D surveys (1978, 1982, 1987, 1993 and 1998) and population projections according to censuses.

\subsection{Projection of trip frequency}

Let us now consider the average number of trips made on a standard weekday in the two regions. While trip frequency is projected to remain fairly stable between 1975 and 2020 in the GPR (approximately 3.4 trips per person per day), a considerable increase in the number of trips is projected during this period in the MRM. This is more difficult to explain and may be at least partially due to the way data was collected in the surveys which has improved over the years to capture more trips.

For the GPR, analysis of the data has led to three main conclusions (Table 7):

- Women make slightly more trips than men (3.45 trips for women and 3.33 for men in 2020).

- Mobility is higher in the central city than in the inner or outer suburbs. But in 2020 the number of trips will be almost identical whatever the zone of residence.

- The more cars owned by a household, the greater the number of trips. Thus, individuals in households without a car in 2005 make an average of 3.09 trips while those in one-car households make 3.44 and those in multi-car households 3.65.

In contrast, in the MRM in 2006, men make more trips than women (respectively an average of 3.01 and 2.94 trips per day) and this should remain the case in 2021. Moreover, residential location appears to have little influence on travel levels. Belonging to a car-owning household is a much more discriminating criterion. It increases trip frequency both for one-car and multi-car households, a result is similar to that obtained for the Greater Paris Region. 
Thus, trip frequency seems to converge for women and men, despite of still specific constraints (Krakutovski, 2004). In both cases, the level of motorization affects the travel levels but residential location appears to have little influence on the number of trips.

Table 7: Projection of trip frequency in the Greater Paris Region (GPR) and in the Metropolitan

Region of Montreal (MRM) by gender, zone of residence and car ownership

\begin{tabular}{|l|r|r|r|r|}
\hline $\begin{array}{l}\text { Trip frequency } \\
\text { (per day) }\end{array}$ & \multicolumn{2}{|c|}{ GPR } & \multicolumn{2}{c|}{ MRM } \\
\hline Projection year & \multicolumn{1}{|c|}{$\mathbf{2 0 0 5}$} & \multicolumn{1}{c|}{$\mathbf{2 0 2 0}$} & \multicolumn{1}{c|}{$\mathbf{2 0 0 6}$} & \multicolumn{1}{c|}{2021} \\
\hline Gender & & & & \\
\hline Male & 3.42 & 3.33 & 2.89 & 3.16 \\
\hline Female & 3.46 & 3.45 & 2.74 & 3.11 \\
\hline Zone of residence & & & & \\
\hline Central city & 3.54 & 3.41 & 2.83 & 3.14 \\
\hline Inner suburbs & 3.42 & 3.41 & 2.78 & 3.08 \\
\hline Outer suburbs & 3.42 & 3.38 & 2.83 & 3.15 \\
\hline Level of car ownership & & & & \\
\hline Households with no car & 3.09 & 3.09 & 2.13 & 2.41 \\
\hline One-car households & 3.44 & 3.39 & 2.98 & 3.33 \\
\hline Multi-car households & 3.65 & 3.53 & 2.96 & 3.29 \\
\hline All & 3.44 & 3.40 & 2.82 & 3.13 \\
\hline
\end{tabular}

Sources: Estimates based for GPR on Global Travel Surveys (1977, 1984, 1992 and 2002) and population projections according to censuses.

Estimates based on the Metropolitan Region of Montreal O-D surveys (1978, 1982, 1987, 1993 and 1998) and population projections according to censuses.

\subsection{Forecast of the distance travelled}

A considerable increase in the total distances travelled in both regions is projected, with this increase being more pronounced in the MRM than the GPR because of the presence of stronger sprawl in the MRM (Table 8).

Table 8: Projected distances travelled in the Greater Paris Region and the Metropolitan Region of Montreal by gender, zone of residence and car ownership

\begin{tabular}{|l|r|r|r|r|r|r|}
\hline $\begin{array}{l}\text { Distance travelled } \\
\text { (per day in km) }\end{array}$ & \multicolumn{3}{|c|}{ GPR } & \multicolumn{3}{c|}{ MRM } \\
\hline Projection year & \multicolumn{1}{|c|}{$\mathbf{1 9 7 5}$} & \multicolumn{1}{|c|}{$\mathbf{2 0 0 5}$} & \multicolumn{1}{c|}{$\mathbf{2 0 2 0}$} & \multicolumn{1}{c|}{$\mathbf{1 9 7 6}$} & $\mathbf{2 0 0 6}$ & $\mathbf{2 0 2 1}$ \\
\hline Gender & & & & & & \\
\hline Male & 16.9 & 19.5 & 20.1 & 9.2 & 16.7 & 18.5 \\
\hline Female & 9.2 & 13.6 & 14.5 & 7.3 & 15.6 & 18.0 \\
\hline Zone of residence & & & & & & \\
\hline Central city & 9.2 & 11.0 & 11.0 & 4.7 & 7.7 & 8.5 \\
\hline Inner suburbs & 11.4 & 13.3 & 13.6 & 8.6 & 13.2 & 14.7 \\
\hline Outer suburbs & 16.9 & 21.3 & 21.9 & 12.8 & 22.9 & 25.8 \\
\hline Level of car ownership & & & & & & \\
\hline Households with no car & 8.1 & 9.3 & 9.2 & 4.8 & 8.0 & 9.7 \\
\hline
\end{tabular}




\begin{tabular}{|c|r|r|r|r|r|r|}
\hline One-car households & 13.6 & 15.1 & 15.0 & 8.6 & 17.2 & 19.6 \\
\hline Multi-car households & 17.8 & 22.1 & 22.8 & 10.4 & 19.9 & 22.3 \\
\hline All & 12.8 & 16.4 & 17.2 & 8.2 & 16.1 & 18.2 \\
\hline
\end{tabular}

Sources: Estimates based for GPR on Global Travel Surveys (1977, 1984, 1992 and 2002) and population projections according to censuses.

Estimates based on the Metropolitan Region of Montreal O-D surveys (1978, 1982, 1987, 1993 and 1998) and population projections according to censuses.

The overall daily distance travelled is projected to increase from $12.8 \mathrm{~km}$ to $17.2 \mathrm{~km}$ between 1975 and 2020 in the Greater Paris Region. In the MRM, the average distance travelled was lower in $1975(8.2 \mathrm{~km})$ but with the progress of urban sprawl the distances travelled will tend to increase greatly and could reach $18.2 \mathrm{~km}$ in 2021. Men in both regions travel greater distances than women. Living farther from the centre increases the distance travelled: in the GPR in 2005, individuals residing in the central city covered an average of $11 \mathrm{~km}$ per day, while those in the inner and outer suburbs covered respectively 13.3 and $21.3 \mathrm{~km}$. The same hierarchy has been observed in the MRM with respective distances of $7.7 \mathrm{~km}, 13.2 \mathrm{~km}$ and $22.9 \mathrm{~km}$. Furthermore, the distance travelled is considerably higher for multi-car households than for one-car and no car households.

\subsection{Results with regard to the average trip distance}

In both regions, our projections reveal a marked tendency for the average trip distance to rise between 1975 to 2020 , from 3.7 to $5 \mathrm{~km}$ in the GPR and 4.5 to $5.8 \mathrm{~km}$ in the MRM.

With regard to gender, the average distance in the Greater Paris Region is considerably higher for men, $5.7 \mathrm{~km}$ compared with $3.8 \mathrm{~km}$ for women in 2005 (Table 9). There is almost no difference between genders in the MRM. In the GPR, the average trip length is considerably greater in the outer suburbs than in the inner suburbs or the central city. This difference is more marked in the MRM, with respectively $8.1 \mathrm{~km}, 4.7 \mathrm{~km}$ and $2.7 \mathrm{~km}$ per trip in 2005 . The same differences should be observed by zone of residence in 2020. Moreover, the household's level of car ownership is a highly discriminating factor in both regions and should remain so in 2020, with the average distance being considerably higher for multi-car households than for one-car and no car households.

Table 9: Estimated average trip distance in the Greater Paris Region and the Metropolitan Region of Montreal by gender, zone of residence and car ownership

\begin{tabular}{|c|c|c|c|c|c|c|}
\hline Average trip distance $(\mathrm{km})$ & \multicolumn{3}{|c|}{ GPR } & \multicolumn{3}{|c|}{ MRM } \\
\hline Projection year & 1975 & 2005 & 2020 & 1976 & 2006 & 2021 \\
\hline Gender & & & & & & \\
\hline Male & 4.6 & 5.7 & 6.0 & 4.7 & 5.7 & 5.8 \\
\hline
\end{tabular}




\begin{tabular}{|l|r|r|r|r|r|r|}
\hline Female & 2.8 & 3.8 & 4.2 & 4.4 & 5.6 & 5.8 \\
\hline Zone of residence & & & & & & \\
\hline Central city & 2.5 & 3.1 & 3.2 & 2.7 & 2.7 & 2.7 \\
\hline Inner suburbs & 3.4 & 3.8 & 3.9 & 4.6 & 4.7 & 4.8 \\
\hline Outer suburbs & 4.9 & 6.1 & 6.4 & 7.2 & 8.1 & 8.2 \\
\hline Level of car ownership & & & & & & \\
\hline Households with no car & 2.6 & 2.9 & 2.9 & 3.1 & 3.8 & 4.1 \\
\hline One-car households & 3.8 & 4.4 & 4.4 & 4.7 & 5.8 & 5.9 \\
\hline Multi-car households & 4.7 & 6.0 & 6.5 & 5.6 & 6.7 & 6.8 \\
\hline All & 3.7 & 4.7 & 5.0 & 4.5 & 5.7 & 5.8 \\
\hline
\end{tabular}

Sources: Estimates based for GPR on Global Travel Surveys (1977, 1984, 1992 and 2002) and population projections according to censuses.

Estimates based on the Metropolitan Region of Montreal O-D surveys (1978, 1982, 1987, 1993 and 1998)

and population projections according to censuses.

\section{Projections of the travel behaviour of seniors}

\subsection{Projections of car ownership}

Ageing seems to reduce car ownership to a considerable degree, because people give up their car as they age, particularly in Montreal with its rigorous winter road conditions, but the age where this occurs tends to rise. Thus, in the MRM, the average age of individuals belonging to a household with no car is projected to increase from 42.8 years in 1976 to 55.4 years in 2021 . These trends are confirmed by an analysis of the distribution of the population according to the number of cars in their household and to age groups. With more pronounced ageing in 2021 , in the MRM $54 \%$ of individuals aged 75 years and over will belong to a household with no car, compared with only $34 \%$ in the GPR.

The elderly should continue to own cars until an advanced age and ageing of the population will modify the general profile of car-owning households, which will tend to become older. Thus, both in the case of one-car and multi-car households, a marked increase in the percentage of elderly is projected. This will induce a marked change in the profiles of drivers in both regions under study.

\subsection{Projection of trip frequency}

Trip frequency indicates that travel behaviour remains dynamic in both regions. For individuals aged 65 and over, the projected increase in the number of trips is greater in the MRM than in the GPR (Table 10). Mobility in the 65-74 year-old age group should thus increase from 2.16 trips in 2005 to 2.92 in 2020 in the MRM, and only from 2.98 to 3.10 in the GPR. Similarly, the number of trips made 
by individuals aged 75 and over is projected to increase from 1.41 in 2005 to 1.97 in 2020 in the MRM and from 2.34 to 2.39 respectively in the GPR.

Table 10: Projection of the trip frequency for elderly persons in the Greater Paris Region and the Metropolitan

Region of Montreal by age, gender, zone of residence and car-ownership

\begin{tabular}{|c|c|c|c|c|c|c|c|c|}
\hline \multirow{3}{*}{$\begin{array}{l}\text { Trip frequency } \\
\text { Age group } \\
\text { Projection year }\end{array}$} & \multicolumn{4}{|c|}{ GPR } & \multicolumn{4}{|c|}{ MRM } \\
\hline & \multicolumn{2}{|c|}{$65-74$} & \multicolumn{2}{|c|}{75 and over } & \multicolumn{2}{|c|}{$65-74$} & \multicolumn{2}{|c|}{75 and over } \\
\hline & 2005 & 2020 & 2005 & 2020 & 2006 & 2021 & 2006 & 2021 \\
\hline \multicolumn{9}{|l|}{ Gender } \\
\hline Male & 3.15 & 3.15 & 2.75 & 2.68 & 2.23 & 2.86 & 1.59 & 2.04 \\
\hline Female & 2.84 & 3.06 & 2.12 & 2.21 & 2.09 & 2.97 & 1.32 & 1.93 \\
\hline \multicolumn{9}{|l|}{ Zone of residence } \\
\hline Central city & 3.31 & 3.32 & 2.74 & 2.75 & 2.17 & 3.01 & 1.44 & 1.98 \\
\hline Inner suburbs & 2.99 & 3.22 & 2.32 & 2.38 & 2.17 & 2.86 & 1.47 & 1.96 \\
\hline Outer suburbs & 2.83 & 2.95 & 2.12 & 2.26 & 2.13 & 2.90 & 1.34 & 1.97 \\
\hline \multicolumn{9}{|l|}{ Level of car ownership } \\
\hline Household with no car & 2.72 & 2.8 & 2.02 & 1.99 & 1.71 & 2.28 & 1.19 & 1.58 \\
\hline One-car household & 3.12 & 3.29 & 2.6 & 2.59 & 2.50 & 3.40 & 1.75 & 2.47 \\
\hline Multi-car household & 2.93 & 3.03 & 2.67 & 2.63 & 2.45 & 3.28 & 1.53 & 2.28 \\
\hline All & 2.98 & 3.1 & 2.34 & 2.39 & 2.16 & 2.92 & 1.41 & 1.97 \\
\hline
\end{tabular}

Sources: Estimates for GPR based on Global Travel Surveys (1977, 1984, 1992 and 2002) and population projections according to censuses.

Estimates based on the Metropolitan Region of Montreal O-D surveys (1978, 1982, 1987, 1993 and 1998) and population projections according to censuses.

The average number of trips made per day diminishes with ageing: in 2005, in the Greater Paris Region under 65 year-olds made on average 3.56 trips per day while 65-74 year-olds made only 2.98 and those aged 75 years and over 2.34 trips per day. The same differences are observed in the MRM where there is an average of 2.98 trips per day under $65 \mathrm{~s}, 2.16$ for $65-74$ year-olds and 1.41 for those aged 75 and over. In contrast to the situation as regards the population as a whole, among the elderly the trip frequency for men is higher than for women in the GPR. While in the MRM there is little difference according to residential location, in the GPR elderly residents of the central city travel more than residents of the inner or outer suburbs. Pertaining to a car-owning household is an even more discriminating criterion among the elderly than for the population as a whole. Thus, in the GPR in 2005, while individuals aged 75 and over who belonged to a household with no car made an average of 2.02 trips per day, those belonging to a one-car household made 2.60. Similarly, in the MRM this age group's trip frequency in 2006 is respectively 1.19 for members of a household with no car and 1.75 for members of a one-car household. 


\subsection{Projections of the distance travelled}

Both among the elderly and the rest of the population, the distances travelled is projected to increase. Thus, in the GPR, the distance travelled by those aged 75 and over should increase from 5.6 $\mathrm{km} /$ day in 2005 to $8.2 \mathrm{~km} /$ day in 2020 (Table 12). The same applies in the MRM, the average distance travelled by those aged 75 years and over being $6.6 \mathrm{~km} /$ day in 2006 and $10.2 \mathrm{~km} / \mathrm{day}$ in 2021 .

The daily distances travelled diminish with age. In 2005 in the GPR while the under 65 yearolds covered an average of $17.7 \mathrm{~km}$ per day, compared with 10.5 for the $65-74$ year-olds, and 5.6 for the over $75 \mathrm{~s}$. In the MRM, the under $65 \mathrm{~s}$ covered an average of $17.2 \mathrm{~km}$ per day, the $65-74$ year-olds covered 11.3 and the group aged 75 and over, 6.6.

As for the population as a whole, the distance travelled by men is higher in both regions; the difference between the distances travelled by the two genders is nevertheless projected to decrease as we approach 2020. With regard to residential zone, the greatest increase in the distance travelled by the elderly should be for residents of the outer suburbs. In the GPR, the average daily distance travelled by persons aged 75 and over living in the outer suburbs could increase by $58 \%$ while for the inner suburbs and the central city, the average increases are respectively $21 \%$ and $29 \%$. Finally, the distance travelled is considerably higher for car-owning households than households with no car in both regions under study.

Table 11: Projection of the distance travelled by the elderly in the Greater Paris Region and in the Metropolitan

Region of Montreal by age, gender; zone of residence and car ownership

\begin{tabular}{|c|c|c|c|c|c|c|c|c|}
\hline \multirow{3}{*}{$\begin{array}{l}\text { Distance travelled by the } \\
\text { elderly (in km per day) } \\
\text { Age group } \\
\text { Projection year }\end{array}$} & \multicolumn{4}{|c|}{ GPR } & \multicolumn{4}{|c|}{ MRM } \\
\hline & \multicolumn{2}{|c|}{$65-74$} & \multicolumn{2}{|c|}{75 and over } & \multicolumn{2}{|c|}{$65-74$} & \multicolumn{2}{|c|}{75 and over } \\
\hline & 2005 & 2020 & 2005 & 2020 & 2006 & 2021 & 2006 & 2021 \\
\hline \multicolumn{9}{|l|}{ Gender } \\
\hline Male & 12.0 & 15.5 & 7.8 & 10.7 & 11.9 & 16.3 & 7.7 & 10.8 \\
\hline Female & 9.2 & 13.7 & 4.4 & 6.7 & 10.8 & 17.0 & 6.0 & 9.9 \\
\hline \multicolumn{9}{|l|}{ Zone of residence } \\
\hline Central city & 8.3 & 9.4 & 5.1 & 6.6 & 5.6 & 7.8 & 3.5 & 5.0 \\
\hline Inner suburbs & 8.5 & 11.3 & 4.8 & 5.8 & 9.7 & 13.0 & 6.5 & 8.9 \\
\hline Outer suburbs & 13.1 & 18.6 & 6.7 & 10.6 & 16.4 & 23.1 & 10.2 & 15.1 \\
\hline \multicolumn{9}{|l|}{ Level of car ownership } \\
\hline Household with no car & 5.2 & 7.5 & 2.8 & 3.3 & 7.2 & 10.5 & 4.7 & 6.9 \\
\hline One-car household & 10.8 & 13.7 & 7.2 & 8.5 & 14.4 & 21.0 & 9.0 & 13.8 \\
\hline Multi-car household & 15.8 & 20.3 & 11.6 & 15.3 & 14.6 & 20.8 & 9.6 & 15.5 \\
\hline All & 10.5 & 14.5 & 5.6 & 8.2 & 11.3 & 16.7 & 6.6 & 10.2 \\
\hline
\end{tabular}

Sources: Estimates for GPR based on Global Travel Surveys (1977, 1984, 1992 and 2002) and population projections according to censuses.

Estimates based on the Metropolitan Region of Montreal O-D surveys (1978, 1982, 1987, 1993 and 1998) and population projections according to censuses. 


\subsection{Results for average trip distance}

The average trip distance is projected to increase more among seniors than the population as a whole. Thus, for $65-74$ year-olds, the average trip distance is projected to increase from $2.3 \mathrm{~km}$ in 1975 to $4.7 \mathrm{~km}$ in 2020 in the GPR and from $3.6 \mathrm{~km}$ to $5.7 \mathrm{~km}$ in the MRM.

In both regions under study, the average trip distances becomes smaller with age, falling from $5.0 \mathrm{~km}$ for the under $65 \mathrm{~s}$, to $3.5 \mathrm{~km}$ for $65-74$ year-olds and to $2.4 \mathrm{~km}$ for those aged 75 and over in the Paris region and respectively from $5.8 \mathrm{~km}$ to $5.2 \mathrm{~km}$ and $4.7 \mathrm{~km}$ in the MRM. The average distances travelled are higher for men (Table 12) in spite of smaller differences among the elderly than the population as a whole. Like for the population as a whole, among the elderly the average trip distance is greater for residents of the outer suburbs than for residents of the inner suburbs and the central city. Likewise, this distance is higher for multi-car households than for one-car or households with no car.

Table12: Estimated average trip distance for elderly in the Greater Paris Region and in the Metropolitan Region of

Montreal by age, gender, zone of residence and car-ownership

\begin{tabular}{|c|c|c|c|c|c|c|c|c|}
\hline \multirow{3}{*}{$\begin{array}{l}\text { Estimated average trip } \\
\text { distance for the elderly } \\
\text { population (in km per day) } \\
\text { Age group } \\
\text { Projection year }\end{array}$} & \multicolumn{4}{|c|}{ GPR } & \multicolumn{4}{|c|}{ MRM } \\
\hline & \multicolumn{2}{|c|}{$65-74$} & \multicolumn{2}{|c|}{75 and over } & \multicolumn{2}{|c|}{$65-74$} & \multicolumn{2}{|c|}{75 and over } \\
\hline & 2005 & 2020 & 2005 & 2020 & 2006 & 2021 & 2006 & 2021 \\
\hline \multicolumn{9}{|l|}{ Gender } \\
\hline Male & 3.8 & 4.9 & 2.8 & 4.0 & 5.3 & 5.7 & 4.8 & 5.3 \\
\hline Female & 3.2 & 4.5 & 2.1 & 3.0 & 5.2 & 5.7 & 4.5 & 5.1 \\
\hline \multicolumn{9}{|l|}{ Zone of residence } \\
\hline Central city & 2.5 & 2.8 & 1.9 & 2.4 & 2.6 & 2.6 & 2.4 & 2.5 \\
\hline Inner suburbs & 2.8 & 3.5 & 2.1 & 2.4 & 4.5 & 4.5 & 4.4 & 4.5 \\
\hline Outer suburbs & 4.6 & 6.3 & 3.2 & 4.7 & 7.7 & 8.0 & 7.6 & 7.7 \\
\hline \multicolumn{9}{|l|}{ Level of car ownership } \\
\hline Households with no car & 1.9 & 2.7 & 1.4 & 1.7 & 4.2 & 4.6 & 3.9 & 4.4 \\
\hline One-car households & 3.5 & 4.2 & 2.8 & 3.3 & 5.8 & 6.2 & 5.1 & 5.6 \\
\hline Multi-car households & 5.4 & 6.7 & 4.3 & 5.8 & 6.0 & 6.3 & 6.3 & 6.8 \\
\hline All & 3.5 & 4.7 & 2.4 & 3.4 & 5.2 & 5.7 & 4.7 & 5.2 \\
\hline
\end{tabular}

\section{Demand-responsive transport}

The two cases analyzed here, in two quite different contexts, one in North America, and the other in Europe, indicate clearly long term structural trends which we might generalize to other cities of the Developed World: private car ownership is likely to continue to dominate future travel demand in many cities of the North, in a context marked by considerable ageing of the population and urban 
sprawl. In both case studies we observed a relation between motorization and high mobility, sprawl and higher distances travelled, ageing and diminishing mobility and car ownership, and longer distances travelled by men. It seems however, that in spite of ageing, in both case studies travel demand will increase in relative terms for the aged population (number of trips per day and distances travelled) and in absolute terms when measured in number of trips or in terms of passenger-kilometres travelled (rising from 1,4 million passenger-kilometres in 1975 to 6,9 million in 2020 in GPR and respectively from 0,2 to 2,7 million passenger-kilometres in MRM for persons aged 75 and over).

We must nevertheless anticipate major changes in modal choices and the appearance of new needs, particularly with regard to demand-responsive transport. Thus, if we consider the Island of Montreal, which corresponds to the central city and inner suburbs in the previous analysis, the modal share of taxi is $0.7 \%$ for $15-74$ year-olds compared with $2.2 \%$ for persons aged 75 and over, i.e. approximately three times higher. The modal shares also change substantially as a result of ageing (Graph 2). Thus, if we compare the group aged 75 and over to 15-74 year-olds:

- there is a reduction in the number of car drivers to the advantage of car passengers;

- $\quad$ surface public transport increases at the expense of heavy modes (train and metro);

- $\quad$ and walking is much more important.

In a situation characterized by population ageing and urban sprawl, demand for taxi should inevitably increase where public transport is deficient in low populated areas and car passengers is not a real alternative for lack of autonomy. The OECD Working Group show that raising the awareness of alternative transport options amongst older drivers will be a key factor in the increase of the mobility of the elderly (Whelon and al, 2006). According to Harris and Tapsas (2006) for older people taxi is the easiest mode of public transport. However, elderly generally do not like to use taxis for two main reasons: they often feel threatened by the aggressive manner of taxi drivers and they see taxis as a luxury that they cannot afford. A subsidised taxi system more readily available would help offset some of these concerns and provide a real alternative transport system particularly for those living in rural and remote areas where public transport is practically non-existent. In Sweden and UK in 2001, a project entitled 'Taxis for All' was set up, which included a review of taxi operation, the development of a prototype accessible taxi, field trial evaluation studies and laboratory based assessments of user 
requirements. The objective was to detect the parameters allowing the accessibility of all the taxis (Oxley and Stahl, 2001).

Ageing is also associated with an increase in disabilities and demand for specialized transport by persons with reduced mobility, which is a specialized form of demand-responsive transport. In the same Metropolitan Areas we observe (Graph 3) an exponential increase in para-transit use by the 75 years or over and which may reach significant rates for some age groups (almost $2 \%$ for those aged 80 or more). Para-transit services, particularly in low density zones, are frequently provided by taxis as they are less expensive than minibuses. There is likely to be an increase in other types of demandresponsive transport for the elderly, for example the use of school buses by voluntary associations for shopping and recreational activities as already exist in some districts of Montreal.

Graph 2: Modal shares of the different transport modes by age, Island of Montreal, 1998

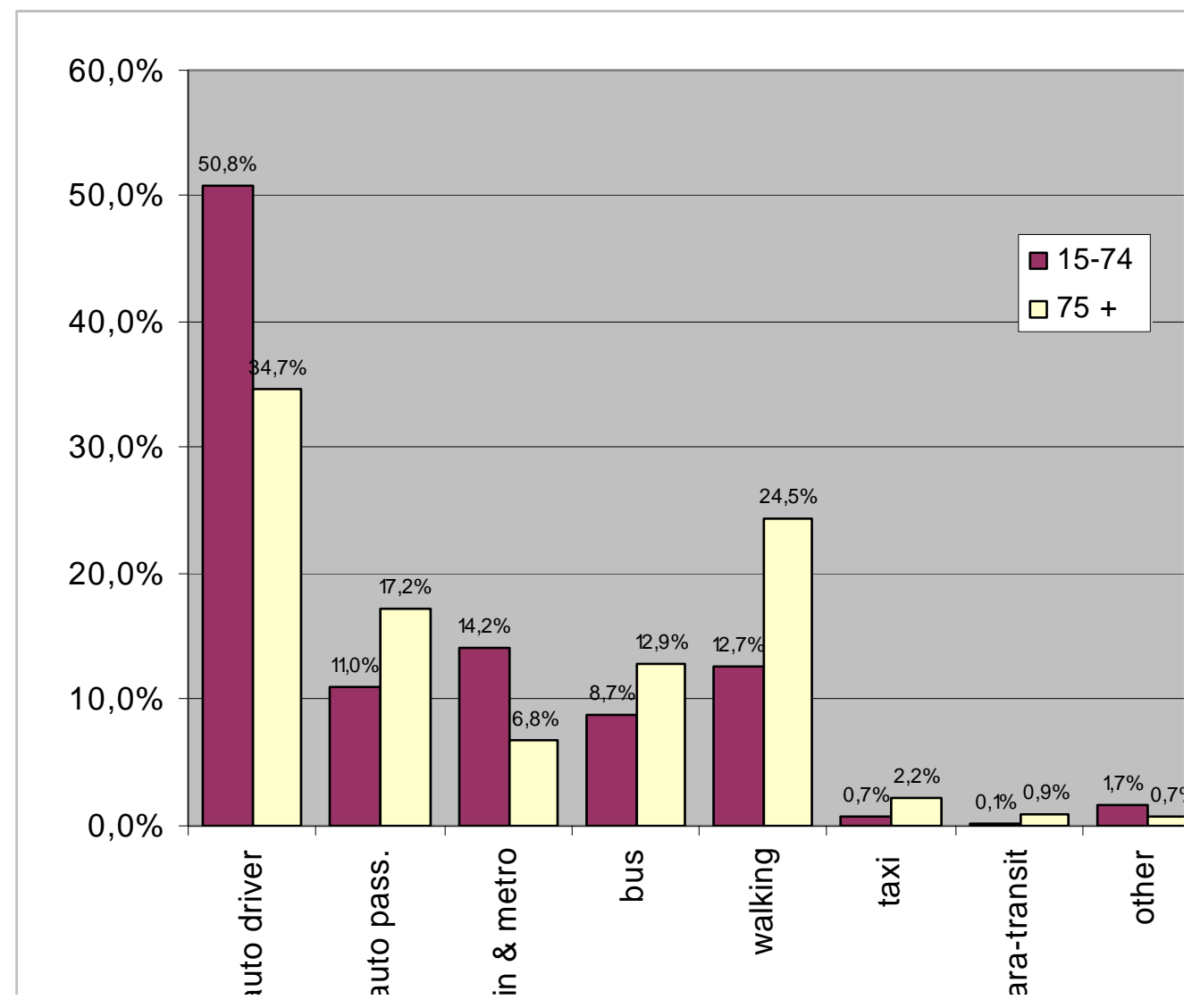

Source: Bussière and Thouez (2002). 


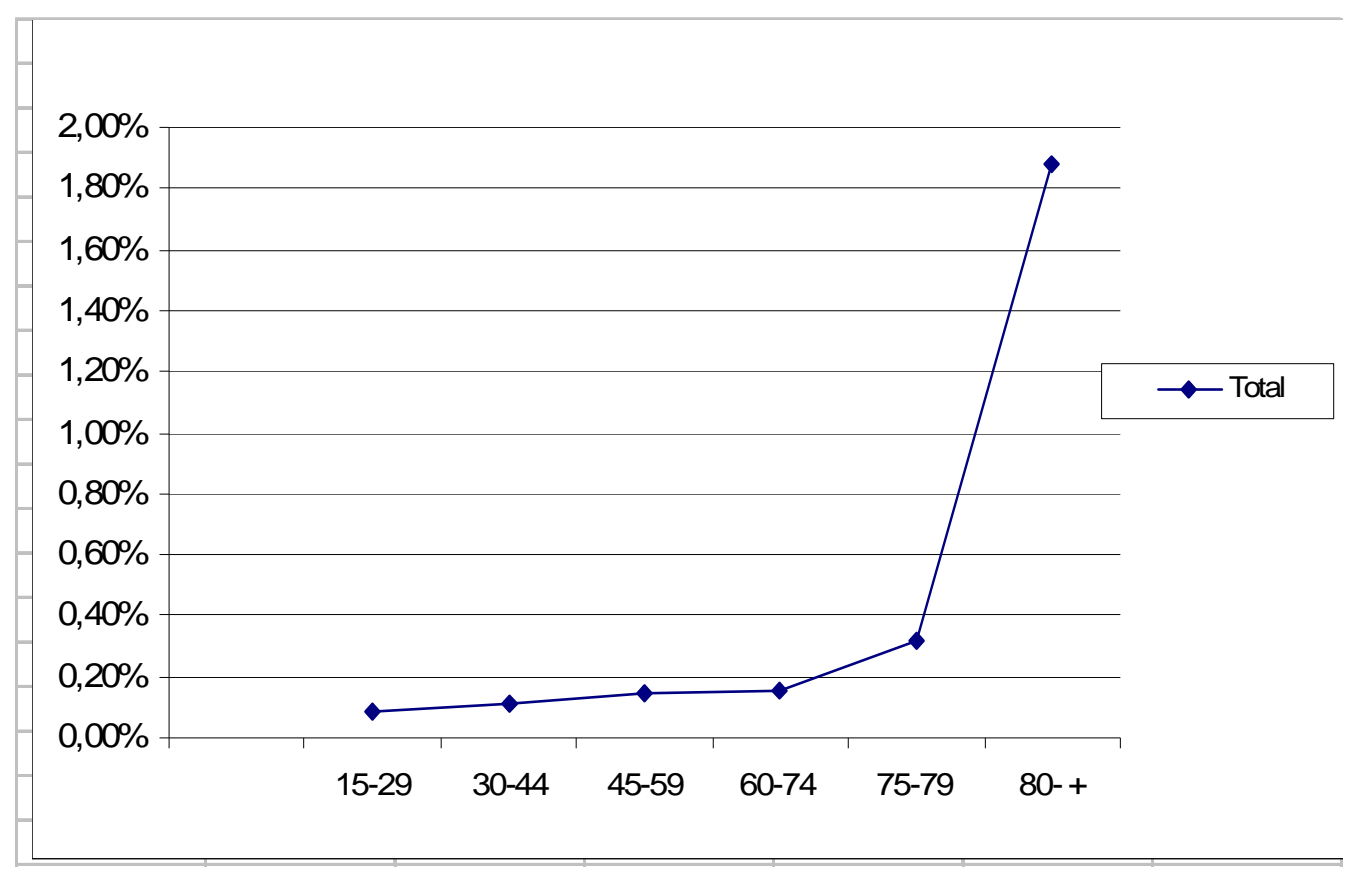

\section{Projection of the demand for taxi in the Greater Paris Region}

In order to estimate changes in the number of taxi trips and the modal share of taxis up to the year 2020, we used the Global Travel Surveys for the Greater Paris Region. Due to the relatively small number of taxi trips it was necessary to aggregate the 1977, 1984, 1992 and 2002 surveys. The modal share of taxi has been computed at the most detailed level, i.e. by crossing the zone of residence, the level of car ownership, gender and age. Then, assuming that these modal shares will remain stable over time and combining the data with the INSEE population projections to the year 2020, we have measured the impact of structural changes in the population, in particular it's ageing, on trip making by taxi. A slight increase in the number of trips made by taxi is projected between 2005 and 2020 in the GPR, with an increase from about 116000 trips to 121000 (Table 13). This is essentially due to individuals aged 65 and over, among whom a $48 \%$ increase in taxi trips is projected over the period. Also, the number of taxi trips should increase by approximately $45 \%$ for residents of the outer suburbs, rising from 25000 trips in 2005 to 36000 in 2020.

Despite the important changes in the structure of the population shown in section 2 , the modal split of trips is projected to exhibit a high degree of stability between 2005 and 2020, being aware that we have made the hypothesis of stable modal shares in each population group. Taxi trips should account for $0.3 \%$ of all the trips in the Greater Paris Region, and this percentage should increase for the elderly and among residents of the outer suburbs. 
Table 13: Projection of the modal share for taxis and the number of taxi trips in the Greater Paris Region by age, zone of residence and car-ownership

\begin{tabular}{|l|c|c|c|c|}
\hline Projection year & \multicolumn{2}{|c|}{2005} & \multicolumn{2}{c|}{2020} \\
\hline Age & $\%$ & $\begin{array}{c}\text { Number } \\
\text { (thousands) }\end{array}$ & $\%$ & $\begin{array}{c}\text { Number } \\
\text { (thousands) }\end{array}$ \\
\hline$<20$ years old & & & 0.14 & 9.9 \\
\hline $20-64$ years old & 0.14 & 9.8 & 0.31 & 77.0 \\
\hline 65 years old and over & 0.33 & 83.2 & 0.66 & 33.9 \\
\hline Zone of residence & 0.62 & 22.9 & & \\
\hline Central city & & & 0.93 & 60.6 \\
\hline Inner suburbs & 0.94 & 65.8 & 0.18 & 23.7 \\
\hline Outer suburbs & 0.19 & 25.0 & 0.20 & 36.4 \\
\hline Level of car ownership & 0.16 & 25.1 & & 48.3 \\
\hline Household with no car & 0.79 & 51.0 & 0.77 & 42.0 \\
\hline One-car household & 0.27 & 43.2 & 0.28 & 30.3 \\
\hline Multi-car household & 0.16 & 21.7 & 0.19 & 120.7 \\
\hline All & 0.32 & 115.9 & 0.32 & \\
\hline \multicolumn{2}{|l|}{$\begin{array}{l}\text { Sources: Estimates based on Global Travel Surveys (1977, } \\
\text { according to censuses. }\end{array}$} & & & \\
\hline
\end{tabular}

\section{Conclusion}

Urban travel demand in cities of the North such as Paris or Montreal will be influenced by a number of structural factors (Kaufmann, 2000), namely demographic ageing, the urban form and household car ownership. In the Greater Paris Region and the Metropolitan Region of Montreal, while the central cities at the end of the 1970s had populations that were considerably older than the inner and outer suburbs, in 2020 the age structures will become much more uniform with a high proportion of older age groups. Ageing will be greater in the MRM than in the GPR, a direct consequence of the very low fertility rates which followed the baby-boom in Montreal, while it stayed relatively high in France. Ageing in the MRM will become comparable with the GPR but with an average age in the suburbs higher than in the GPR.

In both regions, during the last thirty years we have observed urban sprawl, and this trend could continue for the next 20 years. Therefore we could have almost half of the population living in the outer suburbs.

In the Greater Paris Region and Metropolitan Region of Montreal, the age-cohort model predicts major changes in the travel profile of the elderly in the future. The model predicts an increased car ownership, but quite contrasted in the two regions. In the GPR, a decrease in households without a car and an increase in multi-car households; in the MRM, a slight increase in 
multi-motorised households accompanied however with a slight decrease of households without a car, due to a more pronounced ageing.

As for mobility, we observe gender differences between the two regions. In the GPR eldery women have a higher mobility than men but we observe the contrary in the MRM. In both cases mobility rises with car ownership and residential location seems to have little impact on mobility levels. It has however, a significant impact on distances travelled. In the GPR distances travelled are higher for men and directly to the distance of residence from the centre. In the MRM there is almost no difference between genders in average trip length.

In both regions the model predicts an increase in distances travelled and trip length increase with car ownership. In the next 15 years, people aged 75 or over should increase their mileage by $46 \%$ in GPR and by $54 \%$ in MRM. This increase will be higher than for the population as a whole. However, our analysis of the travel profile throughout the life cycle indicates that travel tends to diminish markedly with age as does household car ownership and average trip length. The net impact of ageing as regards the total number of passenger-kilometres travelled will therefore be relatively small by the year 2020 despite the major changes in the profile of the clientele.

Travel demand among the elderly will increase irrespective of their zone of residence. This increase will involve trip frequencies, daily distance travelled and global volume of trips. This will occur in a context of continuing urban sprawl and dependency on motorized modes. In such a context and in both areas, among other impacts, we must anticipate a rapid growth in demand-responsive transport be it conventional taxi, specialized services for persons with reduced mobility (disabilities starting to rise exponentially from the age of sixty), or other forms yet to be invented.

\section{ACKNOWLEDGMENTS}

This research was funded by the French Ministry of Transport under the PREDIT framework program and the ECOS-NORD cooperation program. The authors also acknowledge the valuable comments of three anonymous reviewers.

\section{REFERENCES}

Berri, A. (2005). "Dynamiques de la motorisation et des dépenses de transport des ménages. Analyses sur données individuelles et semi-agrégés, 254p.

Bonnafous, A. (1992). "La croissance du transport en question. Sous-thème 1 : structures 
démographiques et comportements sociaux". Paper presented at the 12th International Symposium on the Transport Economics Theory, CEMT, Lisboa.

Bush, S. (2003). "Forecasting 65+ Travel: An Integration of Cohort Analysis and Travel Demand Modeling," Massachusetts Institute of Technology, Department of Civil and Environmental Engineering, Cambridge, MA, USA.

Bussière, Y., J. Armoogum and J.L. Madre (1996). "Vers la saturation ? une approche démographique de l'équipement des ménages en automobile dans trois régions urbaines". Population, No4-5, pp 955-978.

Bussière, Y. and J.-P. Thouez (2004). "Mobility patterns of the disabled in Montreal in 1998 and long term perspectives", 10th International Conference on Mobility and Transport for Elderly and Disabled People, TRANSED 2004, 23-26 mai, Hamamatsu (Japan). Proceedings.

ECMT, (2000) European Conference of Ministers of Transport. "Transport and Ageing of the Population", round table 112, 260p.

Chapleau, R. (1990). "Recent Trends in Urban Transportation Demand and their Potential Impacts", Global Opportunities for Business in Environment, Vancouver.

Harris, A. and D. Tapsas (2006). "Transport and mobility: Challenges, innovations and improvements. Melbourne, Australia, Roayal Automobile Club of Victoria.

Kaufmann, V. (2000). "Mobilité quotidienne et dynamiques urbaines", Presses Polytechniques et Universitaires Romandes, Lausanne, Suisse.

Krakutovski, Z. (2004). "Améliorations de l'approche démographique pour la prévision à long terme de la mobilité urbaine", thèse de I'Université de Paris XII, 2004, 358 p.

Gallez,. C. (1994). "Identifying the long term dynamics of car ownership: a demographic approach". Transport Reviews, vol. 14, n¹, 83-102.

Insee (2005). "Le modèle de projection démographique Omphale 2000", Insee Method N9112, 2005

Grönvall, O., A. Stahl, M. Bernman (2005) Proceedings of Workshop III, SIZE project, Deliverable D15, Department of Technology and Society, Lund University, Sweden.

Grönvall, O., A. Stahl, M. Bernman (2006) Summary of the results of Area 3, SIZE project, Deliverable D14 and D16, Department of Technology and Society, Lund University, Sweden.

Madre, J.-L. (1990). "Long-term forecasting of car ownership and car use" in Jones, P., Ed., Developements in dynamic and activity-based approaches to travel analysis, Oxford Studies in 
Transport, Avebury, Aldershot.

Madre, J-L., Y. Bussière and J. Armoogum (1995). "Demographic Dynamics of Mobility in Urban Areas: A Case Study of Paris and Grenoble", Proceeding of the $7^{\text {th }}$ WCTR, Sydney, Australia.

Madre, J.-L., J. Armoogum, C. Gallez and Y. Bussière (1996). "Motorisation et mobilité des Franciliens dans les années 2000". Rapport INRETS no 209.

Oxley, P., and A. Stahl (2001) "Taxis for All ? Final Report". Directorate General for Transport, Commission of the European Community. Brussels.

Stahl, A., G. Carlsson, P. Hovbrandt, and S. Iwarsson.(2008)“Let's go for a Walk - Accessibility and Safety for Older People in the Outdoor Environment. Submitted.

U.S. Department of Transportation (2003) "Safe Mobility for a Maturing Society: Challenges end Opportunities". Washington.

Whelan, M., J. Langford, J. Oxley, S. Koppel, J. Charlton (2006). "The elderly and mobility: a review of the literature". Report no 255. Monash University. Accident Research Centre. 